\title{
ANÁLISE GRAVIMÉTRICA DO REVESTIMENTO DE ZINCO-NÍQUEL DE UM AÇO 22MNB5 E ZINCO PURO
}

\author{
Costa, P. D. O. L. ${ }^{1 *}$; Costa, I. ${ }^{1}$; Couto, C. P. ${ }^{1}$; Rossi, J. L. ${ }^{1}$ \\ ${ }^{1}$ Instituto de Pesquisas Energéticas e Nucleares - IPEN \\ Av. Prof. Lineu Prestes, 2242, Cidade Universitária, CEP 05508-00 - São Paulo, SP, Brasil
}

* e-mail: pdolcosta@hotmail.com

\begin{abstract}
Resumo
O aço de alta resistência 22MnB5 é utilizado com revestimento de alumínio-silício com o objetivo de melhorar a resistência a corrosão e desgaste em peças expostas em meios molhados que favorecem o fenômeno corrosivo. Sua principal aplicação é no setor automobilístico englobando peças que integram a estrutura principal do veículo. Uma alternativa para a substituição do revestimento alumínio-silício é uma composição química do revestimento utilizando zinco-níquel. Neste trabalho foi estudado a evolução do processo de perda de massa em diferentes meios corrosivos (ácido, neutro e alcalino) identificando o comportamento do material revestido do aço 22MnB5 e comparando com zinco puro. Foram utilizados três variáveis: revestimento zinco-níquel como recebido, revestimento zinco-níquel estampado e zinco puro. Foi constatado que em meios ácidos ( $\mathrm{pH}$ de 0 a 1) o processo de corrosão foi muito intenso para todos os materiais, do $\mathrm{pH} 3$ ao $\mathrm{pH} 13$ a perda de massa foi insignificante, mesmo sendo imersa durante dias, havendo a proteção do material pela camada passiva formada de óxido. O revestimento estampado se mostrou com maior tendência a perda de massa, por possuir mais defeitos em sua superfície facilitando o processo corrosivo enquanto que o revestimento como recebido se mostrou bem resistente.
\end{abstract}

\begin{abstract}
The 22MnB5 high-strength steel is used with aluminum-silicon coating to improve corrosion resistance and wear on exposed parts in wet environments that favor the corrosive phenomenon. Its main application is in the automotive sector encompassing parts that integrate the main structure of the vehicle. An alternative to replacing the aluminum-silicon coating is a chemical composition of the coating using zinc-nickel. In this work, the evolution of the mass loss process in different corrosive solutions (acid, neutral and alkaline) was studied, identifying the behavior of the coated material of $22 \mathrm{MnB} 5$ steel and comparing with pure zinc. Three variables were used: zinc-nickel coating as received, stamped zinc-nickel coating and pure zinc. It was found that in acid solution ( $\mathrm{pH}$ between 0 and 1) the corrosion process was very intense for all materials, from $\mathrm{pH} 3$ to $\mathrm{pH} 13$ the mass loss was insignificant, even though it was immersed for days, and a passive layer formed of oxide was responsible for the protection. The stamped coating showed to be more susceptible to mass loss because it had more defects in his surface facilitating the corrosive process while the coating as received proved to be very resistant.
\end{abstract}

Keywords (Palavras chaves): Revestimento zinco-níquel, zinco puro, aço 22MnB5, perda de massa.

\section{Introdução}

Atualmente 0 aço de alta resistência 22MnB5 é utilizado com revestimento alumínio-silício sendo aplicado em peças automotivas, reforços de peças dianteiras e traseiras, colunas $B$, reforços laterais, reforços para longarinas dianteiras e longarinas traseiras, assoalhos dianteiros, reforços e travessas de teto, barras de impacto frontal, estrutura de parachoques, peças que integram a estrutura principal do veículo. O aço 22MnB5 já é utilizado como aço de alta resistência em regiões secas de veículos em peças internas que não exigem proteção corrosiva. O revestimento usando alumínio-silício é aplicado ao substrato para aumentar à utilização e resistência a corrosão em peças estruturais da carroceria em regiões molhadas expostas a corrosão e também para permitir a estampagem a quente ${ }^{[1]}$.

Atualmente algumas peças são conformadas por estampagem à quente, sendo elas: reforço da coluna 


\section{Encontro Científico de Física Aplicada}

$A$, reforço da coluna $B$, reforço do teto, barra para a porta, travessas e longarinas ${ }^{[2,3]}$.

Uma alternativa para a substituição do revestimento alumínio-silício é uma composição química do revestimento em zinco-níquel, sendo $85 \%$ a $86,5 \%$ de zinco e $13,5 \%$ a $15 \%$ de níquel (em massa) sobre o aço base $22 \mathrm{MnB5}{ }^{[1]}$. A análise por microscopia eletrônica de varredura para amostras do aço $22 \mathrm{MnB5}$ com revestimento de zinco-níquel estampado apresenta trincas superficiais, mas nenhuma delas atinge o substrato (Figura 1), que é de extrema importância, o que contribuiria para potenciais falhas do material ${ }^{[2]}$.

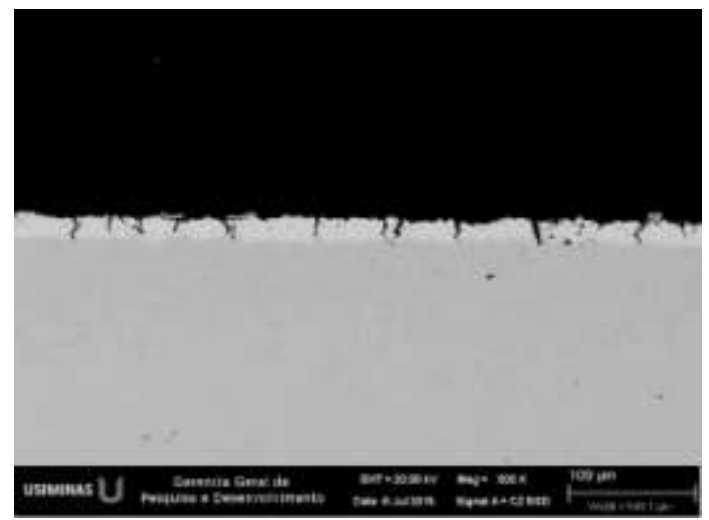

Figura 1: Microscopia eletrônica de varredura para o revestimento zinco-níquel estampado.

Este trabalho teve como objetivo o estudo da perda de massa deste novo revestimento zinco-níquel para analisar seu comportamento nos meios ácido neutro e alcalino, a fim de identificar em quais meios e $\mathrm{pH}$ há uma considerável perda de massa para posteriores ensaios eletroquímicos do mesmo.

\section{Experimental}

Os materiais utilizados para os ensaios gravimétricos foram o aço 22MnB5 revestido com zinco-níquel em duas condições: como recebido (I) e estampado (II) e em uma chapa de zinco puro (III). Os materiais (I) e (II) são de uma chapa de aço 22MnB5, com $1 \mathrm{~mm}$ de espessura, produzida pela aciaria Usiminas, revestidas com zinco-níquel por eletrogalvanização pela empresa ARMCO do Brasil e a estampada realizada sob as condições padrões de estampagem na Benteler Automotive: aquecimento a $900^{\circ} \mathrm{C}$ por 10 minutos e taxa de resfriamento correspondente a $50 \mathrm{~K} / \mathrm{s}$. O material (III) foi comprado de um fornecedor chinês, sendo uma chapa de zinco puro com 99,999\% de pureza e espessura de $0,5 \mathrm{~mm}$. Cada amostra dos três materiais distintos foi lixada em suas laterais e em sua borda para arredondamento, limpas com álcool etanol com o auxílio de algodão e levadas para a limpeza no equipamento de ultrassom dentro de um béquer com $200 \mathrm{~mL}$ de álcool etanol por 5 minutos. Após a limpeza das amostras, com o auxílio de uma pinça limpa foi medido a massa inicial da peça em uma balança de precisão e sua respectiva área com o auxílio de um paquímetro de precisão $0,05 \mathrm{~mm}$.

Os 3 meios de ensaio para a análise gravimétrica foram: ácido nítrico $\left(\mathrm{HNO}_{3}\right)$, cloreto de sódio $(\mathrm{NaCl})$ para o meio neutro e hidróxido de sódio $(\mathrm{NaOH})$ para o meio alcalino, sua molaridade varia de acordo com o $\mathrm{pH}$ a ser utilizado. Para o meio alcalino foi utilizado para o $\mathrm{pH} 14 \mathrm{com}$ molaridade 1, que para um litro de água deionizada equivale a 40 gramas de hidróxido de sódio. Ao término do ensaio, a redução de $\mathrm{pH}$ alcalino é realizada com adição de água deionizada até $\mathrm{opH}$ desejado, o mesmo procedimento ocorre para a solução neutra e para a solução ácida. A medição do $\mathrm{pH}$ é realizada através de um pHmetro, realizando o procedimento de limpeza e calibração do equipamento, para uma medição mais precisa. $O$ ensaio gravimétrico foi realizado com o auxílio de um béquer de $200 \mathrm{~mL}$ com um suporte para o encaixe das amostras dentro da solução. Após 90 minutos, cada amostra foi retirada da solução, limpa com álcool etanol, seca e pesada.

\section{Resultados e discussão}

Os resultados dos ensaios realizados para o $\mathrm{pH}$ ácido $(0,7 ; 1 ; 2 ; 3$ e 4$)$, neutro (6 e 7$)$ e alcalino $(9 ; 11 ; 13$ e 14) para os três materiais são representados com sua média e desvio padrão para os materiais (I) e (II) na Tabela 1, com a perda de massa de cada amostra $\left(\Delta \mathrm{m} / \mathrm{A}\right.$ em $\left.\mathrm{mg} / \mathrm{cm}^{2}\right)$ para 90 minutos de ensaio. O material (III) foi fornecido em pequena quantidade, sendo possível a realização de um ensaio para cada pH estudado.

Tabela 1: Dados dos ensaios para as amostras (I), (II) e (III).

pH $\begin{array}{cccc}\text { Material (I) } & \text { Material (II) } & \text { Material (III) } \\ \left(\mathrm{mg} / \mathrm{cm}^{2}\right) & \left(\mathrm{mg} / \mathrm{cm}^{2}\right) & \left(\mathrm{mg} / \mathrm{cm}^{2}\right)\end{array}$




\begin{tabular}{cccc}
\hline 0,7 & $203,845 \pm 9,730$ & $257,628 \pm 41,598$ & 204,426 \\
\hline 1 & $38,530 \pm 1,344$ & $107,278 \pm 4,189$ & 46,218 \\
\hline 2 & $1,734 \pm 0,397$ & $0,994 \pm 0,135$ & 1,552 \\
\hline 3 & $0,138 \pm 0,013$ & $0,579 \pm 0,187$ & 0,300 \\
\hline 4 & $0,194 \pm 0,019$ & $0,467 \pm 0,150$ & 0,295 \\
\hline 6 & $0,233 \pm 0,022$ & $0,520 \pm 0,284$ & 0,325 \\
\hline 7 & 0 & 0 & 0 \\
\hline 9 & $0,198 \pm 0,011$ & $0,5512 \pm 0,3910$ & 0 \\
\hline 11 & $0,1502 \pm 0,0131$ & $0,5036 \pm 0,2052$ & 0,2463 \\
\hline 13 & $0,2378 \pm 0,0613$ & $0,6518 \pm 0,2507$ & 0,2415 \\
\hline 14 & $2,4456 \pm 0,2948$ & $0,6243 \pm 0,3710$ & 0,4808 \\
\hline
\end{tabular}

Os dados da Tabela 1 plotados em um gráfico de escala logarítmica, fornecem a tendência de curva da Figura 2. Observa-se que para $\mathrm{pH}$ menor que 2, a corrosão é bem intensa nos três tipos de materiais. Para os pH de 3 à 13 o comportamento dos 3 materiais se mantem passivos, devido a proteção de óxido formado em sua superfície, sendo que em $\mathrm{pH} 7$ a perda de massa para 90 minutos de ensaio se mantém nula, mesmo durante dias de imersão na soluções. Para o $\mathrm{pH} 14$ somente o material (I) mostrou um aumento da perda de massa. No geral, o material (II) tem uma maior perda de massa comparado aos outros materiais e o material (I) se mostrou o mais resistente. O material (II), por ser estampado, possui muitas trincas e defeitos em sua superfície (Figura 1), que ocasiona uma maior corrosão do mesmo.

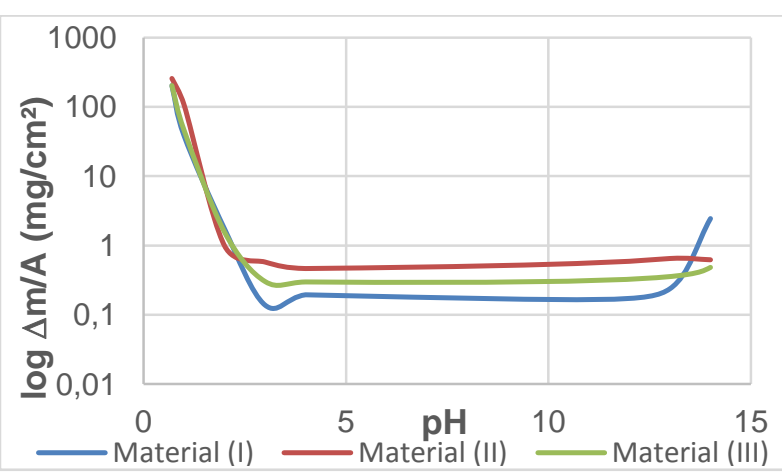

Figura 2: Perda de massa em função do pH para os materiais (I), (II) e (III).

Para analisar melhor o comportamento observado em pH's abaixo de 2, um ensaio extra foi realizado. 0 procedimento consiste em mergulhar a amostra na solução de pH 1, logo após realizada sua lavagem com álcool e sua secagem, assim a amostra é colocada em solução de $\mathrm{pH} 2$ e então o procedimento se torna o mesmo dos ensaios gravimétricos anteriores, afim de observar se, com a quebra da camada passiva, a perda de massa progride ou se ocorre uma nova passivação. A Tabela 2 mostra os dados dos ensaios em comparação com os ensaios gravimétricos de pH 2 . Notou-se que para o material (I) houve um aumento significativo no valor de perda de massa, para o material (II) triplicou e no material 2 houve o dobro de perda, confirmando a quebra da camada passiva.

Tabela 2: Dados dos ensaios para as amostras (I), (II) e (III)

\begin{tabular}{cccc}
\hline $\mathbf{p H}$ & Material (I) & Material (II) & Material (III) \\
\hline 2 & 1,7346 & 0,9941 & 1,5528 \\
\hline $1 \rightarrow 2$ & 2,2305 & 3 & 3,6982 \\
\hline
\end{tabular}

\section{Conclusão}

A análise gravimétrica nos três materiais estudados teve uma grande perda de massa em pH menor que 1 . No intervalo de $\mathrm{pH} 3$ à 13 a perda de material foi muito pequena, por conta da camada passiva protegendo todos os materiais. O material (II) de revestimento estampado mostrou-se o mais suscetível à corrosão, por conta de muitos defeitos em sua superfície e o material (I) foi o mais resistente em todos os meios de ensaio.

\section{Referências}

[1] GORNI, A. A. Aços avançados de alta resistência: Microestrutura e propriedades mecânicas. Corte \& Conformação de Materiais, 4:44, Dezembro 2008, 2657.

[2] COUTO, C. P. Estudo da difusividade dos elementos químicos presentes nos revestimentos $\mathrm{Al}-\mathrm{Si}$ e Zi-Ni sobre o aço $22 \mathrm{MnB} 5$ durante o processo de estampagem a quente. 115 f. Monografia, Centro Universitário Fundação Santo André, Santo André, 2015.

[3] KARBASIAN, H.; TEKKAYA, A. E. A review of hot stamping. Journal of Materials Processing

Technology. v. 210, p. 2103-2118, 2010. 